C. G. L. Furmidge and A. J. Low are four eminent members of the board, selected for mention here because they represent distinct yet overlapping interests in the field of pesticides. The new journal considers for publication work relating to the production and use of pesticides, including those used in veterinary and public health. It also accepts articles covering the ecological and economic implications of their use. Papers in the first two issues of volume one do indeed cover a wide range of interests. It is, however, noteworthy that, while the effect of pesticides on organisms receives attention in several excellent articles, these first two numbers do not seem to do full justice to the complementary subject of the effect of organisms on pesticides. Yet such practically important matters as field performance, persistence, safety and selectivity of action are frequently dependent on the rate and the route a substance is metabolized. The editorial board of Pesticide Science undoubtedly recognizes this fact, and it is to be hoped that this apparent weakness in these first two issues is a consequence of pure chance, rather than to the absence of the word "metabolism", from the list of subjects which authors are told will be considered for publication.

With this one reservation, Pesticide Science promises to be a valuable new medium both for disseminating and for acquiring information on this rapidly expanding multidisciplinary subject.

KenNeTH Hassall

\section{FIGHT THE GOOD FIGHT}

\section{The Ecologist}

Edited by E. R. D. Goldsmith. Vol. 1, No. 1. Monthly. (Ecosystems: London, July 1970.) $4 s$ per issue; $40 s$ per annum.

THE bandwagon of environmental crusaders has had the brakes on lately, in Britain at least, but the publication this month of the first issue of The Ecologist promises a further lunge forward into new seas of effluent and deserts of dereliction. The magazine is by no means the detached and cautious scientific review that its title might suggest; indeed, insofar as it deals with ecology at all, The Ecologist dwells in a man-centred ecosphere and largely in those parts of it which man is supposed to be damaging beyond repair. What the editor, Mr Edward Goldsmith, is anxious to communicate is "the fact that there is a serious emergency", to be attacked fundamentally by checking the growth of population and by dispelling the myth of unrealistically high standards of living.

To this end, Mr Goldsmith has set up his own publishing company, Ecosystems Ltd, which is producing 60,000 copies of the first issue of The Ecologist for sale on the bookstalls or by subscription. In the contributed articles, environmental hypochondria is kept well under control. Professor R. Lindsay Robb, for example, argues the case for closer links between medicine and agriculture, suggesting that since both practices are concerned with human welfare they should be controlled by a common ministry. $\mathrm{Mr}$ Robert Allen, the assistant editer, also writes illuminatingly about the conflicting interests of the Eskimos and the oil companies in Alaska.

Some of the editorial comment, however, is on less firm ground. "Organisms that obtain mastery over their environment become over-specialized"--from which it is paradoxically made to follow that "they are at the mercy of the slightest environmental change that might create a situation to which they no longer have the means of adapting". Another item deplores the amount of money invested in art, in comparison with the difficulty of raising cash for conservation, and talks of "pseudoconcepts" of which "one of the most pernicious . . . is anthropocentric evaluation". This aggressive creed, coming from a magazine which is called The Ecologist but whose subject matter is principally man himself, may seem just a little surprising.

\section{Short Notices}

The Origins and Growth of Modern Education. By Elizabeth Lawrence. Pp. 393. (Penguin: Harmondsworth,
April 1970.) 10s.

MoDERN educational ideas are not modern at all-they owe their heritage to the Romans, and their line can be traced unbroken through the Roman, Renaissance and Victorian eras. Elizabeth Lawrence, who has investigated the pedigree of "progressive" educational ideas with all the thoroughness of a genealogist, supports her theory with so many quotations that they take up more space than basic text. Twenty-five centuries of educational thinking are packed into the book, and educationalists from Socrates to A. S. Neill of Summerhill school play their part in the lineage. Although entrenched opponents of progressive education are unlikely to be won over by appeals to history, this book provides a useful compendium of educational quotations.

Scienza e Tecnica. Annuario della EST, Enciclopedia Scienza e della Tecnica. Pp. 566. (Mondadori: Milan, 1970.) 14,000 lire.

THE third in this series of scientific yearbooks maintains the outstanding qualities of its predecessors, notably in the eminence of its contributors and the excellence of the design and illustrations. The section on space, for example, contains articles by Dr Donald Rea of NASA on the exploration of Mars and by Dr Vladimir Kurt of the University of Moscow on that of Venus; there are also articles on the exploration of Jupiter and the outer planets, the launch system for the Apollo missions and the guidance and propulsion of space vehicles. The other sections of the yearbook, all of them of equal or nearly equal merit, are devoted to astrophysics, geophysics, the environment and philosophy of science. Even at 14,000 lire (£9 7s) the book is of good value.

The Wild Mammals of Malaya and Offshore Islands, including Singapore. By Lord Medway. Pp. xix +127 +15 plates. (Oxford University Press: London and Kuala Lumpur, June 1970.) 125s.

IN the states of Malaya and the adjacent offshore islands, including Singapore, it is illegal to capture or kill the Javan and Sumatran rhinoceroses, the apir, the pangolin, the binturong, three species of gibbon and the slow loris, and there are also several other species of wild land mammals out of a total of 199 in the region that are protected in some way. It would be wise therefore for the naturalist intent on a game hunt to read this book, which should give him sufficient clues to an animal's identity - a brief description is accompanied by notes on distribution, habits and life history, and there are handsome illustrations by Mazli Matsom and Hamidah Suhaimi.

The Royal Botanic Garden Edinburgh, 1670-1970. By H. R. Fletcher and W. H. Brown. Pp. xvi $+309+20$ plates. (HMSO: Edinburgh and London, 1970.) $72 s$.

STUDENTs of the history of science whose appetite for botanical memorabilia was whetted by the recent article in Nature on Edinburgh's Royal Botanic Garden (226, 904; 1970) will find the full story of three centuries of floristic endeavour in this scholarly book. This is the story of the development of a forty foot square physic garden, founded in 1670 by Andrew Balfour and Robert Sibbald, into seventy-five acres of plants, greenhouses, exhibition areas and research facilities. It is also part of the story of botany's disengagement from medicine and its emergence as a science in its own right, as each new keeper and curator brought new plants and ideas to Edinburgh. The text is enhanced by a fine collection of plans and pictures which illustrate many phases of the garden's Browth. 